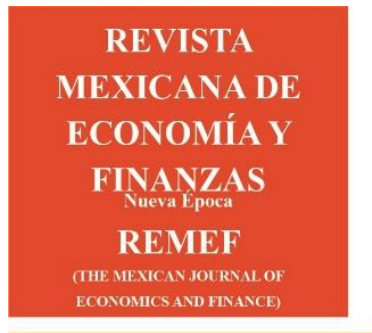

Revista Mexicana de Economía y Finanzas, Nueva Época

Volumen 15 Número 4, Octubre - Diciembre 2020, pp. 745-767

DOI: https://doi.org/10.21919/remef.v15i4.553

(Recibido: 31/marzo/2020, aceptado: 29/junio/2020)

Special Issue: Energy \& Growth

Guest Editor: Ilhan Ozturk, Ph.D.

\title{
On the Interaction among Economic Growth, Energy-Electricity Consumption, CO2 Emissions, and Urbanization in Latin America
}

\author{
Humberto Valencia-Herrera ${ }^{1}$ \\ Tecnológico de Monterrey, México \\ Roberto J. Santillán-Salgado ${ }^{2}$ \\ Tecnológico de Monterrey, EGADE Business School, México \\ Francisco Venegas-Martínez ${ }^{3}$ \\ Instituto Politécnico Nacional, Escuela Superior de Economía, México
}

\section{Abstract}

This paper is aimed at studying the dynamics and long-run interaction among changes in $\mathrm{CO} 2$ emissions, economic growth, changes in energy and electricity use, and changes from rural to urban population among Latin American countries (LA) during the period from 1990 to 2014. A Panel VEC (VAR) approach using data from the World Bank shows that the first and second differences in the log of the proportion of the urban population to total population explain: CO2 emissions, GDP per capita, energy-electricity per capita, and the urbanization process. Moreover, CO2 emissions are cointegrated with the first difference in the $\log$ of the proportion of urban population. The empirical results show no evidence of the existence of an environmental Kuznets curve. Moreover, it is not possible to generalize the nature of the economic growth-energy consumption-urbanization and $\mathrm{CO} 2$ emissions relationships across different latitudes. Finally, a limitation of this study is that the limited availability of data for several countries in the LA region restricts the scope of the econometric analysis.

JEL Classification: Q56, Q54, Q43

Keywords: CO2 emissions, economic growth, energy policy, urbanization, Latin America.

\section{Sobre la interacción entre crecimiento económico, consumo de energía- electricidad, emisiones de CO2 y urbanización en América Latina}

\section{Resumen}

Esta investigación tiene como objetivo estudiar las interacciones dinámicas de largo plazo entre los cambios en las emisiones de $\mathrm{CO} 2$, el crecimiento económico, los cambios en el uso de energía y electricidad, y los cambios de la población rural a la urbana en América Latina (AL) durante el período 1990-2014. Un enfoque de datos panel VEC (VAR) con datos del Bancc Mundial muestra que la primera y segunda diferencias de los logaritmos de la proporción de la población urbana con respecto a la población total explican: emisiones de $\mathrm{CO} 2$, PIB per cápita, consumo de energía, electricidad per cápita y el proceso d urbanización. Además, las emisiones de $\mathrm{CO} 2$ se cointegran con la primera diferencia con el logaritmo de la proporción de la población urbana. Los resultados empíricos no sugieren evidencia de la existencia de una curva ambiental de Kuznets. Tampoco es posible generalizar la naturaleza de las relaciones de crecimiento económico-consumo de energía-urbanización y emisiones de $\mathrm{CO} 2$ en diferentes latitudes. Una delimitación de este documento es la disponibilidad limitada de datos para varios países de AL, lo cual restringe el alcance del análisis econométrico

Clasificación JEL: Q56, Q54, Q43

Palabras clave: Emisiones de CO2, crecimiento económico, política energética, urbanización, América Latina.

\footnotetext{
${ }^{1}$ Email: humberto.valencia@tec.mx

${ }^{2}$ Email: roberto.santillan@tec.mx

${ }^{3}$ Email: fvenegas1111@yahoo.com.mx

* Sin fuente de financiamiento para el desarrollo de la investigación.
} 


\section{Introduction}

The interaction among economic growth, energy consumption, and $\mathrm{CO} 2$ emissions has been extensively studied because of its significant implications in public policy that arise from such an interaction (Ozturk and Acaravci, 2010; Saidi and Hammami, 2015; Gorus and Aydin, 2019; and Salazar-Núñez et al., 2020). Probably, the main concern of ecologists, governments, and NGOs, among others, about this interaction has to do with the damaging effects of $\mathrm{CO} 2$ emissions continuously released to the atmosphere changing weather patterns, global warming, melting perpetually frozen regions and, most importantly, the economic and demographic consequences associated to those phenomena. The combustion of fossil fuels for electricity generation, transportation, and other numerous economic activities are becoming the primary source of $\mathrm{CO} 2$ emissions, which has an impact on the planet's atmosphere average temperature that affects weather patterns, which has a negative impact for many countries, mainly those highly dependent on agricultural activities and tourism.

Several Latin American (LA) countries enjoy the benefits of abundant hydrologic resources that may be used to produce electricity from hydroelectric plants to satisfy a good part of their energy needs and, in principle, are less exposed to the consequences of CO2 pollution (Solarin and Ozturk, 2015; and De Barbosa et al., 2017). However, the urban development and rapid industrialization of many countries in the region (Brazil, Mexico, Chile, and Colombia, among others) requires a fast energy-supply growth that can only be achieved through conventional sources, i.e., fossil fuels as petroleum derivatives, gas, and coal. LA Countries with lower levels of economic development need more and more energy to detonate the modernization of their productive structures.

The conflict from the increasing demand for energy associated with economic growth and the negative impact that fossil fuels consumption has on environmental pollution has been a mainstream topic in the literature for several years (see, for example, Antonakakis et al., 2017). Beckerman's (1992) seminal work is among the first to discuss that the pollution effects of $\mathrm{CO} 2$ released from fossil fuels on the environment are closely associated with economic growth. Beckerman questions the need for rigorous measures to control the risk of global warming. The author also argues that $\mathrm{CO} 2$ emissions control should not be considered an urgent problem by governments and authorities. He proposed that the emphasis of public opinion and government attention should be re-directed to other more transcendental challenges. The bottom line of Beckerman's argument is that emerging economies do not have the alternative to slow down their economic growth to reduce environmental pollution because their population, frequently very large, has an urgent need to improve its living standards (Richard, 2012). In this case, cleaner energy sources cannot produce the supply that is needed to support fast economic growth rates. Beckerman also pioneered the idea that as economies grow, they become more environmentally friendly, and will eventually reverse the environment deterioration that took place during the early stages of development. Subsequently, Gao and Zhang (2014) and Demir et al. (2019) developed and documented this idea empirically; generally identified as the Environmental Kuznets Curve (EKC). Kuznets' (1953) inverse curve of income inequality represents the idea of a progressive migration of the poor agricultural sector's population towards a prosperous industrial sector in which only those that make that transition benefit from better salaries as their labor becomes more productive. The industrial workers now receive better salaries, and this is what it causes an increase in income inequality. The more agricultural workers migrate towards, the more they enjoy better living standards, and income inequality diminishes. However, this stylized mechanism can be understood in more general terms; for example, in the description of the country's development and its collateral effects 
on the environment. In this case, during the first phases of industrialization, pollution is aggravated, and the ecology's damage becomes generalized. Nevertheless, gradually, greater responsibility, increasing pollution control measures, and greater efficiency in energy use eventually reduces the damage to the environment. The EKC is represented as a graphical relationship between economic development, measured as GDP per capita (in a horizontal axis), and pollution effects measured in terms of $\mathrm{CO} 2$ emissions per capita (in a vertical axis). The inverted $U$ shape suggests that as countries increase their GDP per capita, environmental pollution first increases, then it reaches an area of stability, and finally, it diminishes. For example, Dinda (2004) writes that during the early stages of economic development, the environment deteriorated faster than income growth due to industrialization and urbanization, but that deterioration slows down at higher income levels. The EKC has been extensively studied and documented (e.g., Aldy, 2005; Gao and Zhang, 2014; and Demir et al, 2019). Nevertheless, the EKC has been challenged because there is no a common agreement on the breaking point where the increasing pollution trend changes direction, i.e., at what personal income levels is the deterioration of the environment expected to slow down and begin to improve. The vast diversity of research works that have attempted to empirically document the EKC is not conclusive. The problem of environmental degradation that accompanies economic development is a complex multi-dimensional problem. The structural characteristics of countries are very different; the response of governments and social organizations of multilateral entities is also very different from one case to another. Furthermore, the relationship between environmental degradation and economic growth also presents changing characteristics through time as economic growth and $\mathrm{CO} 2$ emissions in crosscountry comparisons (Ahmad et al., 2016; Ajmi et al., 2015; Chang, 2010; Gao and Zhang, 2014; Niu et al. 2011; and Zambrano-Monserrate et al., 2018).

From the above discussion, the main conclusion is that based on the sometimes contradictory evidence reported in the literature, it is unlikely that any particular policy can successfully reduce the environmental pollution in all cases. As economies grow following different development paths, it becomes clear that there is a need for more specific models that objectively incorporate the interaction between the economy and the environment. The identification of which factors play a relevant role on the EKC is until the present not only a theoretical question, which is increasingly understood, but also an empirical challenge due to the specificities that prevail in different countries and regions, and through different periods. Thus, research on this nexus must have a high priority on the agenda; good government policies may only be designed and implemented once the drivers of the EKC are identified. However, Dinda (2004), based on an extensive review of studies that report empirical evidence on the EKC, suggests that structural econometric models are required instead of reduced models to better understand the nature of the underlying variables. The possibility that technological change and structural change interact in the determination of the EKC makes decomposition analysis a useful approach to improve the understanding of the phenomenon.

This paper reintroduces the relevance of the urbanization process on energy use, economic growth, and $\mathrm{CO} 2$ emissions. It shows for Latin-American countries its relevance to explaining the development in the region, its impact on the use of energy, and its contribution to the main driver of global change: $\mathrm{CO} 2$ emissions. It also contributes to the literature showing different results with the variables considered for Latin-America.

The following section presents a brief overview of the empirical literature on the interaction among economic growth, energy consumption, and $\mathrm{CO} 2$ emissions with specific reference to the few studies available for LA countries. 


\section{A Brief Literature Review}

There is ample literature on the relations among economic growth, energy consumption and $\mathrm{CO} 2$ emissions. The importance of the subject is considerable, as it relates to the material well-being of modern societies, which has significant economic consequences for large industries (electricity generation, oil extraction, refining and transportation, and new energy sources activities). Besides, it is present in the design and implementation of public policy at different government levels.

Some of the studies that have focused on such a interaction for developed countries are, for instance: Cai et al. (2018), Acaravci and Ozturk (2010), Ajmi et al. (2015), Ang (2007), Mikayilov et al, (2018), and Bartleet and Goounder (2010). Besides, numerous studies include large samples of countries (Huang et al., 2008; Narayan and Popp, 2012; Saidi and Hammami, 2015; Antonakakis et al., 2017) or have focused in emerging countries (Ahmad et al, 2016; Saboori et al., 2012; Ozturk and Acaravci, 2010; Demir et al., 2019; Chang, 2010; Ghosh, 2010; Tiwari et al., 2013; Alam et al., 2011; Zhang and Cheng, 2009; Zhang, 2011), or in cross-country studies (Gao and Zhang, 2014; Demir et al., 2019; Heidari et al., 2015; Niu et al., 2011; Gorus and Aydin, 2019; Apergis and Payne, 2009), and at an ad-hoc grouping that includes either countries of a similar level of economic development (e.g., BRICs, OECD countries) (Pao and Tsai, 2010; Bella et al., 2014; and Aali-Bujari et al. 2017), or some of them focus on to a given international association because they share some specific economic interest, even when they are geographically distant (e.g., OPEP) (Squalli, 2007).

Another important strand of the literature on the interaction of economic growth, energy consumption, and $\mathrm{CO} 2$ Emissions responds to the relative abundance of studies on the subject, attempting to redefine the limits of the different matters of interest. Literature review papers recover the contribution of numerous individual pieces of research, classifying them according to their primary subject matter, critically discuss them, and delineate future avenues of progress in research. Some of the most recent literature review studies in the field include: Tiba and Omri (2017), Kaika and Zervas (2013), Omri (2014), Ozturk (2010), Payne (2010), and Dinda (2004). The organization of these papers focuses on the empirical evidence reported by the literature on four core research schemes (Ozturk, 2010). The first line of research tests whether there is bidirectional causality between economic growth and energy consumption, a subject of the utmost importance as the role of governments and the strategic decisions of firms may be influenced by confirmatory evidence (Ghali and El-Sakka, 2004; Akinlo, 2008; and Richard, 2012). A second line studies the existence of causality from the consumption of electricity towards economic growth, giving electricity the status of a driver of progress and modernization, which implies that constraints on the use of energy are likely to inhibit economic growth (Narayan and Smyth, 2008; Ozturk, 2010; and Payne, 2010). A third line analyzes the possible effects of energy conservation and environmentally responsible measures on economic growth, i.e., whether the regulatory and policy measures imposed by governments constrain economic growth (Payne 2010; and Richard, 2012). Finally, the fourth line of research suggests the inexistence of neutrality between economic growth and energy consumption (Wolde-Rufael, 2005; Halicioglu, 2009; and Pablo-Romero and De Jesús, 2016).

The literature review papers mentioned above are, in all cases, highly comprehensive, analytical, and relevant. However, the most recent, that of Tiba and Omri (2017) only includes papers published as late as 2014. This section briefly mentions some of the relevant papers on the subject that have appeared since that year. It highlights the comprehensive approach that has recently prevailed, including the simultaneous interaction among economic growth, energy consumption, and $\mathrm{CO} 2$ emissions. The new 
approach has overcome the limitations of earlier studies. Some representative studies are mentioned here because its relationship with the present study. The more current studies include, for example, Demir et al. (2019) investigating the impact of income distribution on environmental quality in Turkey under the EKC framework, and conclude that increasing income inequality reduces environmental degradation in Turkey. On the other hand, Gorus and Aydin (2019) study eight oil-rich MENA countries, and using a panel frequency domain approach conclude that energy conservation policies do not have an adverse effect on economic growth; Cai et al. (2018) investigate the relations among clean energy, economic growth and $\mathrm{CO} 2$ emissions for the G7 countries and find that clean energy consumption causes real GDP in six of the seven countries in their sample; Antonakakis et al. (2017) perform a comprehensive study of 106 countries to analyze the relationship among different types of energy consumption, economic growth and $\mathrm{CO} 2$ emissions and find no statistically significant evidence that renewable energy consumption is conducive to economic growth; and Cerdeira-Bento and Moutinho's (2016) research examines the relations among CO2 emissions, economic growth, and electricity production (from renewable and non-renewable sources), as well as their interaction with foreign trade (1960-2011) in Italy. Also, Ahmad et al. (2016) analyze the interaction among CO2 emissions, energy consumption, and economic growth in India, an emerging market. Kasman and Duman (2015) study the energy consumption, CO2 emissions, and economic growth relationships among several EU, new participants and candidate countries. Ajmi et al. (2015) revise the G7 member countries, arguing that there is a constant transformation of the relation among energy consumption, $\mathrm{CO} 2$ emissions, and economic growth explained by the intense regulatory activity and dynamic technological progress observed in those countries. Heidari et al. (2015) are interested in the founding members of the Association of Southeast Asian Nations ${ }^{4}$ (ASEAN) to test the presence of the EKC based on a Panel Smooth Transition Regression (PSTR), and reject the hypothesis of linear association among economic growth, energy consumption, and CO2 emissions. Finally, Saidi and Hammami (2015) estimate a Dynamic Panel Data model to study the impact of economic growth and $\mathrm{CO} 2$ emissions on energy consumption for 58 countries and report that the impact of economic growth on energy consumption has a positive and statistically significant effect.

As mentioned previously, the academic studies interest has been increasingly focused on the nexus of energy consumption, economic growth, and environmental pollution, and that is the case also in those studies that focus on Latin American countries. While the available literature is by no means as extensive as in cross-country or country studies, there are significant contributions. Some examples include the work of Al-Mulali et al. (2013), which explores the bi-directional relationship among energy consumption, economic growth, and $\mathrm{CO} 2$ emissions for a sample of 32 Latin American and Caribbean countries. The authors report that " $56 \%$ of the countries have positive bi-directional long-run relationships between energy consumption and economic growth, $6 \%$ have a long run bi-directional negative relationship between energy consumption and economic growth, $16 \%$ of the countries were found to have a positive one-way long-run relationship between energy consumption and economic growth, $16 \%$ of the countries have a long-run positive relationship between economic growth and energy use, and $6 \%$ of the countries have no relationship between energy consumption and economic growth". These are necessary measurements for the design and implementation of energy policies, as they may impact economic growth in a significant way. Following a similar approach, Chang and Soruco Carballo (2011) aim to identify in which of the

\footnotetext{
${ }^{4}$ The founding members of ASEAN (in 1967) were Indonesia, Malaysia, Philippines, Singapore, and Thailand. Recently, in 2010, Vietnam, Brunei, Myanmar, Cambodia, and Laos joined the organization.
} 
twenty Latin American and Caribbean countries included in their sample it is possible to implement energy conservation policies with the aim to curve down environmental deterioration and global warming that, avoiding a negative effect on economic growth. The results reported, based on cointegration analysis, Vector Autoregression (VAR) and Vector Error Correction (VECM) models suggest that only four countries (Argentina, the Dominican Republic, Mexico, and Panama) are in a position to adopt energy conservation measures without affecting economic growth. Zambrano-Monserrate et al. (2018) analyze the relationship among economic growth (GDP), $\mathrm{CO} 2$ emissions, renewable electricity consumption, natural gas, and oil consumption (all variables in per capita terms) for Perú (1980-2011). With the estimation of an ARDL model to test cointegration and Granger causality analysis based on a VECM, the results indicate that there is no support for the EKC relationship. Thus, the authors conclude that the country cannot rely on an eventual reduction of environmental pollution as a consequence of higher GDP. For that reason, Peru must implement policies to minimize greenhouse gas emissions by adopting alternative energy sources.

By contrast, a study that confirms the presence of the EKC in Latin America and the Caribbean is that of Al-Mulali et al. (2015). They use a Fully Modified OLS (FMOLS) model and find an inverted Ushape relationship between $\mathrm{CO} 2$ and GDP, which confirms the existence of the EKC. The same study also found that financial development improved environmental quality through its negative long-run effect on $\mathrm{CO} 2$. However, renewable energy consumption has no long-run effect on $\mathrm{CO} 2$, meaning that the emphasis on this type of energy is not contributing to reducing CO2 emissions. Pao and Tsai (2010) utilize Grey's prediction model to foresee the evolution of the relationship between $\mathrm{CO} 2$ emissions, energy consumption, and economic activity for Brazil (1980-2007) and find that there is strong pair-wise bidirectional causality between the three variables. These authors recommend that Brazil should adopt a strategy of investments in energy infrastructure that will support the country's economic development efforts and, at the same time, implement energy conservation policies to increase energy efficiency. Tateishi et al. (2017) also examine the relationship between economic growth, CO2 emissions, and the consumption of energy in Brazil (19702013) through time series econometric techniques (VAR and VECM). The authors report that there is a positive influence of short-term energy consumption towards economic growth. However, energy consumption also seems to impact CO2 emissions, much in line with the results of Pao and Tsau (2010), notwithstanding they use sample data for different (although overlapping) periods.

\section{Data and Methodology Used in the Analysis}

This paper studies the dynamic and long-run relationships among changes in CO2 emissions, economic growth, changes in energy and electricity use, and changes from rural to urban population among LatinAmerican countries during the period 1990-2014 by using panel VEC and VAR methodology. The sample includes the following countries: Argentina, Bolivia, Brazil, Chile, Colombia, Costa Rica, Dominican Republic, Ecuador, El Salvador, Guatemala, Haiti, Honduras, Mexico, Nicaragua, Panama, Paraguay, Peru, Uruguay, and Venezuela. The variables considered in the analysis are metric tons of carbon dioxide emissions per capita (CO2C); gross domestic product per capita (GDPC) in constant United States dollars of 2010; energy use per capita (ENEC) expressed in kilograms of oil equivalent per capita; electricity use per capita (ELEC) in kilowatts hours per capita, and the proportion of urban population with respect to the total population (URBP) expressed in percentage terms. The series for each country (CO2C, GDPC, ENEC, ELEC, and URBP) have ten or more years of concurrent data in the WBDB; only those countries that met that requirement are included in the sample. 
The analysis is conducted following several dynamic hypotheses on Latin American countries economic growth, energy consumption, $\mathrm{CO} 2$ emissions, and urbanization relationships:

a) $\mathrm{CO} 2 \mathrm{C}$ increases (decreases) with previous-year increases (decreases) in GDPC, ENEC, or ELEC. That is, the changes in the logarithm of $\mathrm{CO} 2 \mathrm{C}$ increases (decreases) with previous year increases (decreases) in the logarithm of GDPC, ENEC, or ELEC.

b) The logarithm of $\mathrm{CO} 2 \mathrm{C}$ increases (decreases) with decreases (increases) in oneyear changes in the logarithm of URBP.

c) The marginal change of $\mathrm{CO} 2 \mathrm{C}$ to the previous-year marginal change of GDPC decreases with increases in the GDP.

In the long run, we also study the following cointegration hypotheses:

d) The long-run logarithm of $\mathrm{CO} 2 \mathrm{C}$ increases (decreases) with increases (decreases) in the logarithm GDPC, ENEC, or ELEC in LA countries.

e) The long-run logarithm CO2C increases(decreases) with decreases (increases) in the one-year change of the logarithm of URBP in Latin American countries.

The analysis is performed with the estimation of two VEC (VAR) models. Model A includes the following system of equations:

$$
Y=f(X)+e
$$

where Y represents first differences in the logs of CO2C, GDPC, ENEC, and ELEC, and the second difference in the log of URBP, $f(\cdot)$ is a matrix of linear functions, $X$ are one-year lagged differences (or second differences) of the $\log$ of the variables, and $e$ is the vector of errors. Model $\mathrm{B}$, in which $Y$ is as in Model A, and $X$ are previous years one-year changes (or second changes) in the logarithm of CO2C, GDPC, ENEC, ELEC, and URBP. The models can include cointegration equations if appropriate, including the variables in levels (or differences), depending on the results of unit-root tests. The procedure followed includes the next steps: Analysis of the data, Analysis of stationarity of each series, and its first (second) differences, if appropriate. Determination of the number of lags of the independent variables (model B) and the number of cointegrated equations. Analysis of results.

\section{Estimation Results and Interpretation}

Table 1 presents the descriptive statistics of the database. Part A reports all variables in levels and reveals that they have a smaller standard deviation than their mean and right skewness. The exception is URBP, with a small negative skewness (-0.05). Part B presents the descriptive statistics of the natural logarithm of the variables, which all exhibit smaller means and standard deviations and a skewness more to the left than the original variables. Part $\mathrm{C}$ contains the summary statistics of the first differences of natural logarithms. In the case of URBP, it also reports the second difference, given its unit-root properties, which is discussed later on. During the period of study, all variables increased through time. So the first difference of their logarithm is always positive. The case of URBP, in particular, as it exhibits concavity, is measured by the mean of the second difference of its $\log$, which is negative (-0.0002). 
Table 1. Descriptive statistics of main variables

A. Data in Levels

\begin{tabular}{|c|c|c|c|c|c|c|}
\hline Variable & Observations & Mean & $\begin{array}{c}\text { Standard } \\
\text { Deviation }\end{array}$ & Skewness & Kurtosis & Minimum \\
\hline CO2C & 475 & 1.99 & 1.53 & 1.45 & 4.73 & 0.04 \\
\hline GDPC & 475 & $9,455.35$ & $4,812.15$ & 0.33 & 2.25 & $1,509.63$ \\
\hline ENEC & 474 & 913.28 & 508.93 & 1.22 & 3.62 & 188.95 \\
\hline ELEC & 475 & $1,236.06$ & 866.68 & 0.78 & 2.84 & 18.68 \\
\hline URBP & 475 & 67.05 & 15.63 & -0.05 & 2.10 & 28.51 \\
\hline
\end{tabular}

B. Natural logarithm of variables

\begin{tabular}{|c|c|c|c|c|c|c|}
\hline Variable & Mean & $\begin{array}{c}\text { Standard } \\
\text { Deviation }\end{array}$ & Skewness & Kurtosis & Minimum & Maximum \\
\hline $\operatorname{lnCO} 2 \mathrm{C}$ & 0.39 & 0.82 & -0.66 & 4.27 & -3.23 & 2.04 \\
\hline $\ln$ GDPC & 8.99 & 0.62 & -0.79 & 3.11 & 7.32 & 10 \\
\hline $\ln \mathrm{ENEC}$ & 6.68 & 0.52 & 0.2 & 2.83 & 5.24 & 7.84 \\
\hline $\ln \mathrm{ELEC}$ & 6.77 & 1.02 & -1.52 & 5.95 & 2.93 & 8.26 \\
\hline $\ln \mathrm{U}$ RBP & 4.18 & 0.25 & -0.55 & 2.93 & 3.35 & 4.55 \\
\hline
\end{tabular}

C. First differences in the logarithms of the variables

\begin{tabular}{|c|c|c|c|c|c|c|}
\hline Variable & Mean & $\begin{array}{c}\text { Standard } \\
\text { Deviation }\end{array}$ & Skewness & Kurtosis & Minimum & Maximum \\
\hline dlnCO2C & 0.0200 & 0.1190 & 0.6400 & 23.2700 & -0.8110 & 1.0800 \\
\hline $\mathrm{d} \ln \mathrm{GDPC}$ & 0.0200 & 0.0350 & -0.8100 & 5.5800 & -0.1460 & 0.1510 \\
\hline $\mathrm{d} \operatorname{lnENEC}$ & 0.0160 & 0.0570 & 0.4800 & 9.1400 & -0.2700 & 0.3820 \\
\hline $\mathrm{d} \operatorname{lnELEC}$ & 0.0320 & 0.0800 & 0.1300 & 16.1300 & -0.4240 & 0.5380 \\
\hline $\mathrm{d} \ln \mathrm{U}$ RBP & 0.0080 & 0.0070 & 1.9100 & 8.7000 & 0.0000 & 0.0450 \\
\hline $\mathrm{d} 2 \ln \mathrm{URBP}$ & -0.0002 & 0.0020 & 2.0700 & 83.6100 & -0.0190 & 0.0280 \\
\hline
\end{tabular}

Source: Own elaboration, with data from the WBDB

The positive trend followed by the average of the database variables is observable in all the panels of Figure 1. The graphs of GDPC and ENEC show steady increases with minor variations each year and an accelerated growth since 2003. URBP also maintains a very steady uprising trend throughout the observation period. The case of ENEC and ELEC is different in the sense that both show a fall in 2014. 


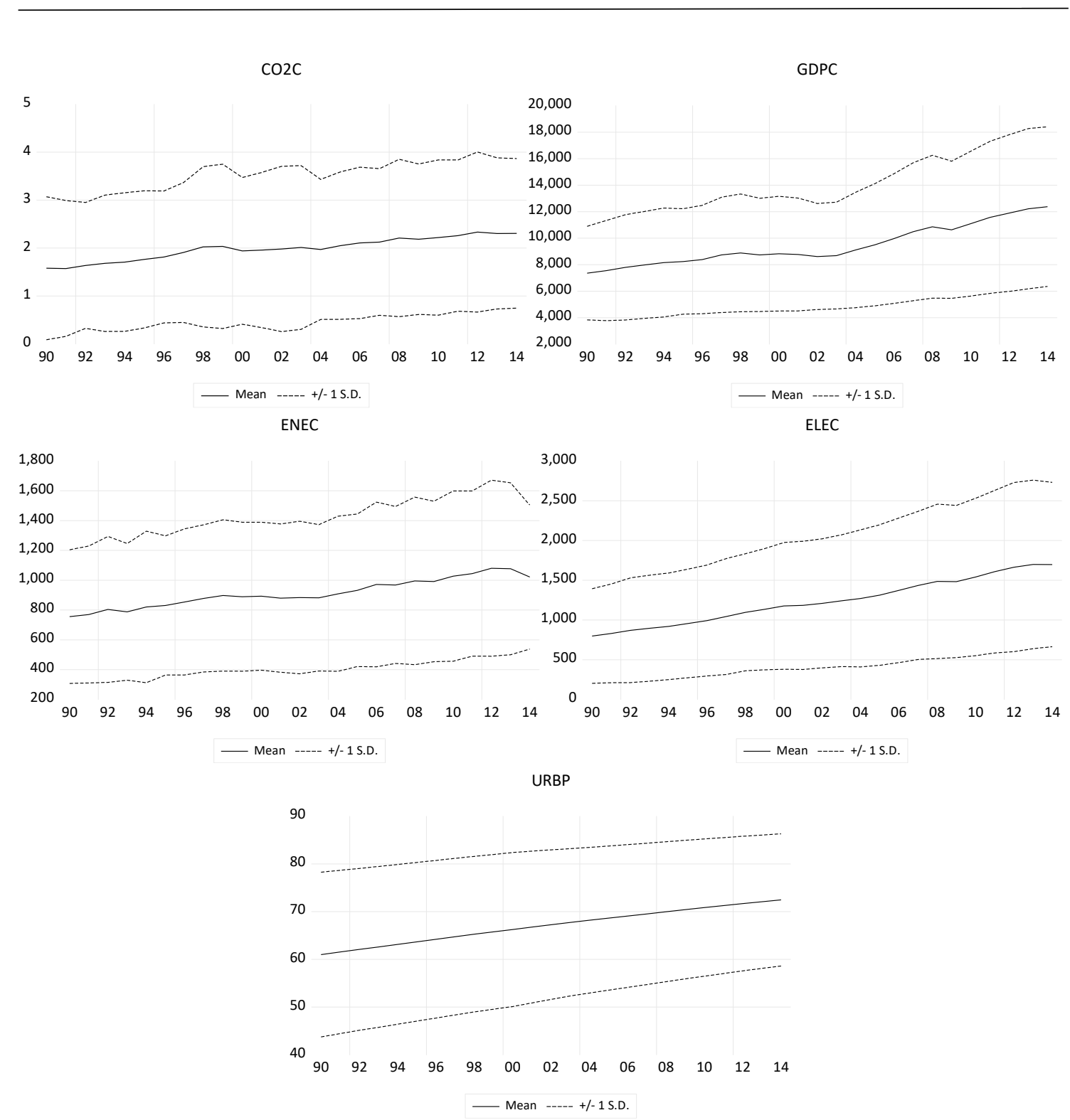

Figure 1. Dynamics of the main variables

Source: Own elaboration, with data from the WBDB

A Pearson pairwise correlation analysis of the first differences of the variables in logs considering the wholes study period is presented in Table 2. Strong correlations are observed between CO2C and GDPC (0.231), CO2C and ENPC (0.446), CO2C and ELEC (0.284), GDPC and ENEC (0.298), GDPC and ELEC (0.391), and ELEC and ENEC (0.309). Negative correlations are observed for GDPC and URBP (-0.160), URBP and ENEC (-0.012), and URBP (second differences) and ELEC (-0.099). 
Table 2. Long-run Pearson pair-wise cross-correlations

\begin{tabular}{|c|c|c|c|c|c|c|}
\hline & dlnCO2C & dlnGDPC & dlnENEC & dlnELEC & dInURBP & d2InURBP \\
\hline dlnCO2C & 1 & & & & & \\
\hline dlnGDPC & 0.231 & 1 & & & & \\
\hline dlnENEC & 0.466 & 0.298 & 1 & & & \\
\hline dlnELEC & 0.284 & 0.391 & 0.309 & 1 & & \\
\hline dlnURBP & 0.029 & -0.16 & 0.011 & -0.099 & 1 & \\
\hline d2lnURBP & 0.059 & 0.069 & -0.012 & 0.077 & 0.105 & 1 \\
\hline
\end{tabular}

Source: Own elaboration, with data from the WBDB.

Figure 2 shows short-term Pearson pair-wise cross-correlations of the first differences of the log of $\mathrm{CO} 2 \mathrm{C}$ and the differences of the logs of the other variables in Table 2, considering subperiods of three years, centered in the indicated year. The cross-correlation of the difference of the logs of CO2C and ENEC towards the end of the period of analysis is larger than at the beginning. On the contrary, the crosscorrelations of the log differences of CO2C and GDPC and CO2C and ELEC are larger at the beginning

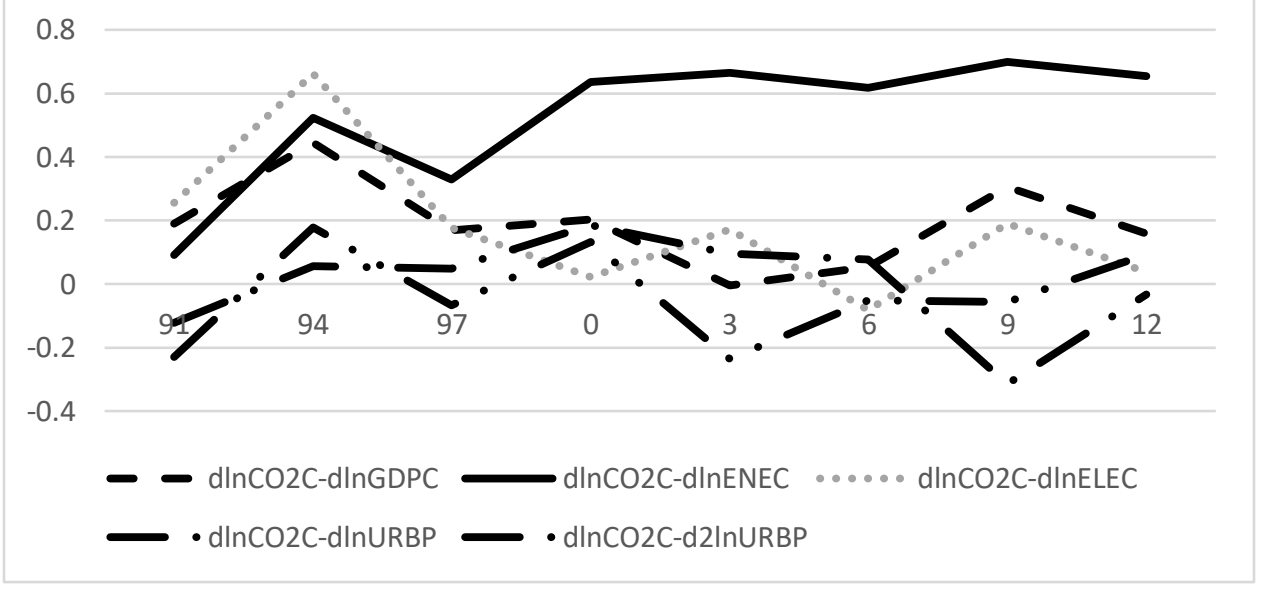

Figure 2. Short-term Pearson cross-correlations.

Source: Own elaboration, with data from the WBDB

The results reported in Table 3 refer to the Augmented Dickey-Fuller (ADF) panel tests on the logarithm of each series to determine their stationarity. The test did not reject the null hypothesis that all panels contain unit roots at a significance level of one percent. However, in the case of CO2C and URBP, the ADF test rejected the null hypothesis with a five percent of significance. For the first differences of the logarithm of the series, the ADF test rejects the null that all panels have unit roots at a significance level of one percent. The exception is URBP, in whose case the test rejected the null for the second difference. The cross-sectional means were removed before the tests, following Choi (2001). Therefore, the series are stationary in first differences, except the logarithm of URBP, which is in second differences. 
Table 3. Augmented Dickey Fuller stationarity test

\begin{tabular}{|l|c|l|}
\hline Variable & Z Statistic & \multicolumn{1}{|c|}{ p-value } \\
\hline $\operatorname{lnCO} 2 \mathrm{C}$ & -1.794 & 0.036 \\
\hline $\ln \mathrm{GDPC}$ & -0.439 & 0.33 \\
\hline $\ln \mathrm{ENEC}$ & 0.357 & 0.64 \\
\hline $\ln \mathrm{ELEC}$ & -0.679 & 0.248 \\
\hline $\ln \mathrm{URBP}$ & 1.049 & 0.853 \\
\hline dlnURBP & -1.761 & 0.039 \\
\hline
\end{tabular}

\begin{tabular}{|c|c|c|}
\hline Variable & Z Statistic & p-value \\
\hline $\mathrm{d} \operatorname{lnCO} 2 \mathrm{C}$ & -13.459 & 0 \\
\hline $\mathrm{d} \operatorname{lnGDPC}$ & -9.448 & 0 \\
\hline $\mathrm{d} \ln E N E C$ & -10.488 & 0 \\
\hline $\mathrm{d} \operatorname{lnELEC}$ & -10.113 & 0 \\
\hline $\mathrm{d} 2 \ln U R B P$ & -12.402 & 0 \\
\hline
\end{tabular}

Note: Augmented Dicker Fuller test with one lag and inverse normal distribution and Ho: All panels contain unit roots. Cross-sectional means removed following Choi (2001).

Source: Own elaboration, with data from the WBDB.

Based on the previous results, the econometric approach followed in the analysis of the interaction among economic growth, energy consumption, $\mathrm{CO} 2$ emissions, and urbanization consists of the estimation of two models. Model (A) considers only short and long-term effects, while Model (B) considers short, medium, and long-term effects. Model A only considers one-period lagged variables, while Model B is flexible in the sense that it can include from one to as many lags as necessary to minimizes the overall Akaike Information Criterion (AIC). In each case, Johansen Cointegration Tests (JCT) were estimated to determine if cointegration equations were needed and, if so, how many (see Table 4). In the case of Model A, the JCT suggests the presence of only one cointegration relationship. Based on the trace test, the probability of no cointegration is 0.01 percent (i.e., the test is rejected at a one percent significance level). The probability of "at most one cointegration equation" is 7.60 percent (i.e., the test is not rejected at conventional significance levels). According to the maximum eigenvalue (ME) statistic, the probability of no cointegration is 0.02 percent (i.e., the test is rejected at a one percent significance level). However, the probability of "at most one cointegration equation" is 6.84 percent (i.e., the test is not rejected at conventional significance levels). Both statistics suggest the existence of at least one cointegrating vector, and this evidence supports the choice of a VECM for Model A.

Tabla 4. Johansen cointegration test, Model A

Unrestricted Cointegration Rank Test (Trace)

\begin{tabular}{|c|c|c|l|}
\hline $\begin{array}{c}\text { Hypothesized number } \\
\text { of cointegration } \\
\text { equations(s) }\end{array}$ & Trace Statistic & $\begin{array}{c}\mathbf{0 . 0 5} \\
\text { Critical } \\
\text { Value }\end{array}$ & Probability** \\
\hline None * & 96.809 & 69.819 & 0.0001 \\
\hline At most 1 & 45.867 & 47.856 & 0.0760 \\
\hline At most 2 & 19.373 & 29.797 & 0.4663 \\
\hline
\end{tabular}




\section{Unrestricted Cointegration Rank Test (Maximum Eigenvalue)}

\begin{tabular}{|l|r|r|l|}
\hline $\begin{array}{c}\text { Hypotesized number } \\
\text { of cointegration } \\
\text { equations(s) }\end{array}$ & $\begin{array}{c}\text { Maximum } \\
\text { Eigenvalue } \\
\text { Statistic }\end{array}$ & $\begin{array}{c}\mathbf{0 . 0 5} \\
\text { Critical } \\
\text { Value }\end{array}$ & Probability** \\
\hline None $*$ & 50.9410 & 33.8770 & 0.0002 \\
\hline At most 1 & 26.4940 & 27.5840 & 0.0684 \\
\hline At most 2 & 11.403 & 21.1320 & 0.6071 \\
\hline \multicolumn{2}{|r|}{ Source: Own elaboration, with data from the WBDB. } \\
\hline
\end{tabular}

Table 5 presents the estimation results for the VECM of Model A. The evidence suggests that the $\log$ of $\mathrm{CO} 2 \mathrm{C}$ has statistically significant long-term relationships with changes in the log of URBP. However, the relation with the log of GDPC is not statistically significant, although the variable has the right sign (positive). The log of CO2C increases with the log of GDPC, ENEC, and the first difference in URBP, but decreases with the log of ELEC. That is, the cointegration equation shows that the $\log$ of $\mathrm{CO} 2 \mathrm{C}$ is statistically cointegrated with the one-year change of the log of URBP, and the coefficients of the other variables are not statistically significant.

In the short run, the first difference of the $\log$ of $\mathrm{CO} 2 \mathrm{C}$ is mean-reverting because the coefficient on its one-year lagged change is negative and greater than minus one (-0.289). It is also statistically dependent on the first lag of dlnGDPC, and the lagged convexity (concavity) (second difference) of URBP (11.661). The sensitivity of dlnCO2C to $\operatorname{lnENEC}$ and $\operatorname{lnELEC}$ is positive, but not statistically significant. dlnGDPC statistically depends on its first lag (0.2640), on the lagged dlnURBP (1.712) and the cointegration equation (-0.002). dlnENEC is also mean reverting because the coefficient of dlnENEC is 0.21 , and this variable is also statistically dependent on the lagged dlnGDPC (0.247). dlnELEC is also mean reverting because the coefficient of the lagged dlnELEC in the is -0.108 , and this variable is also statistically dependent on the cointegration equation $(-0.002)$. $\mathrm{d} 2 \ln U \mathrm{RBP}$ is only statistically dependent on the cointegration equation $(-0.0001)$ and its first lag (0.0989).

Table 5. Vector Error Correction one-lag Model

\begin{tabular}{|l|r|}
\hline Cointegrating Equation: & \multicolumn{1}{c|}{ Coint1 } \\
\hline $\ln C O 2 C$ & 1.000 \\
\hline $\ln \mathrm{GDPC}$ & 3.330 \\
\hline $\operatorname{lnENEC}$ & 3.791 \\
\hline $\operatorname{lnELEC}$ & -2.879 \\
\hline dlnURBP & $699.672 *$ \\
\hline C & -41.928 \\
\hline
\end{tabular}




\begin{tabular}{|l|r|r|r|r|r|}
\hline Error Correction & \multicolumn{1}{|c|}{ dlnCO2C } & \multicolumn{1}{c|}{ dlnGDPC } & \multicolumn{1}{l|}{ dlnENEC } & \multicolumn{1}{l|}{ dlnELEC } & \multicolumn{1}{l|}{ d2lnURBP } \\
\hline Coint1 & -0.0010 & $-0.0020^{*}$ & 0.0010 & $-0.0020^{*}$ & $-0.0001^{*}$ \\
\hline dlnCO2C(-1) & -0.2890 & -0.0070 & 0.0080 & 0.0440 & 0.0007 \\
\hline dlnGDPC(-1) & $0.2410^{*}$ & $0.2640^{*}$ & $0.2470 *$ & 0.2060 & 0.0028 \\
\hline dlnENEC(-1) & 0.1860 & 0.0430 & $-0.2130^{*}$ & 0.0580 & -0.0001 \\
\hline dlnELEC(-1) & 0.0110 & -0.0160 & 0.0320 & $-0.1080^{*}$ & -0.0012 \\
\hline d2lnURBP(-1) & $11.6610^{*}$ & $1.7120^{*}$ & -0.7140 & -0.1310 & $0.0989^{*}$ \\
\hline C & $0.0220^{*}$ & $0.0150^{*}$ & $0.0130 *$ & $0.0300^{*}$ & -0.0002 \\
\hline Adjusted $R$-Squared & 0.0980 & 0.1250 & 0.0320 & 0.0170 & 0.0633 \\
\hline Akaike Information Criterion (AIC) & -1.5340 & -4.0020 & -2.8590 & -2.1980 & -9.4032 \\
\hline & & & & & \\
Overall Akaike information criterion & -20.654 & & & &
\end{tabular}

* Statistically significant at the 95 percent level Source: Own elaboration, with data from the WBDB

The relations described in the previous paragraphs are confirmed by observing the impulse response diagrams in Figure 3.

Response to Cholesky One S.D. (d.f. adjusted) Innovations
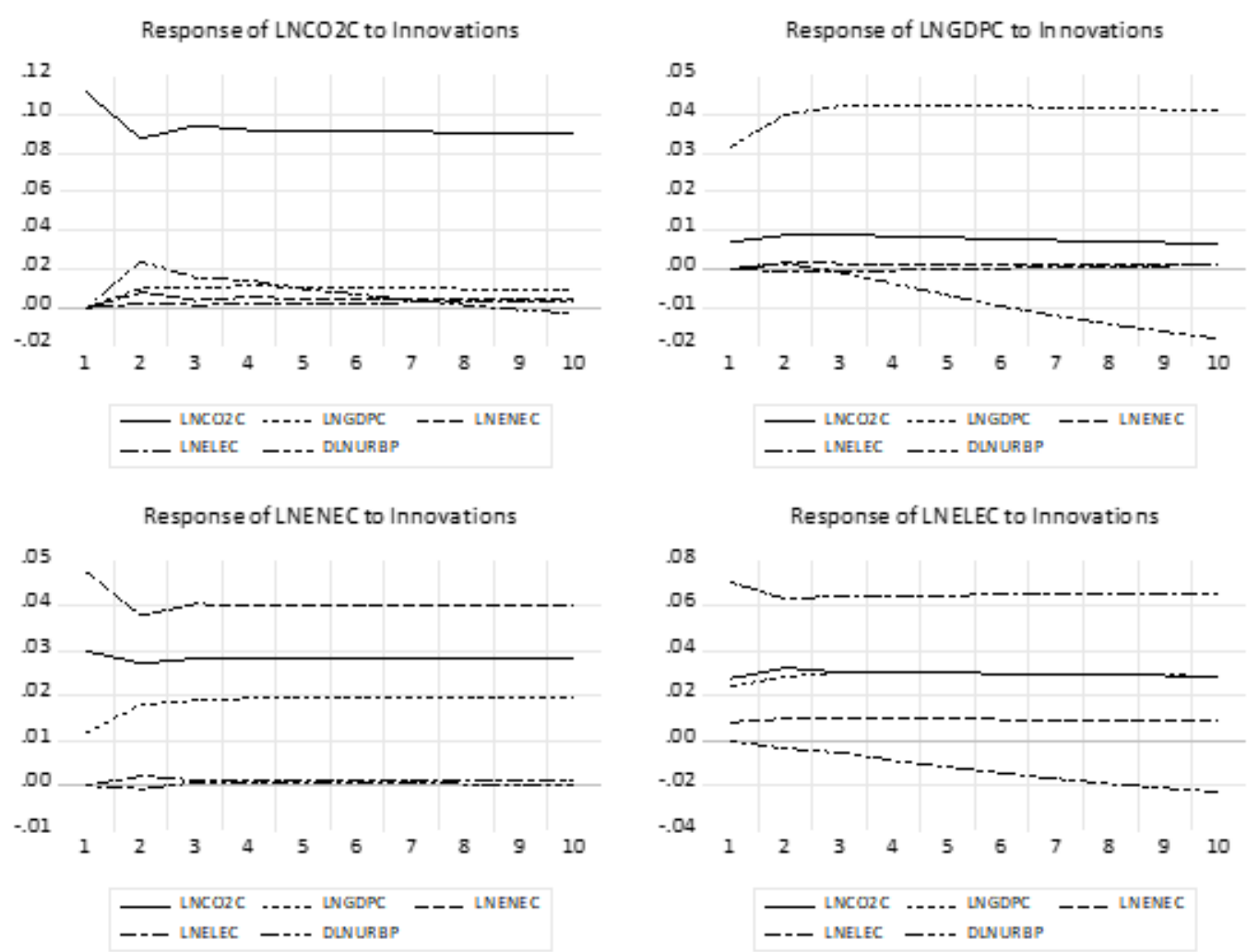


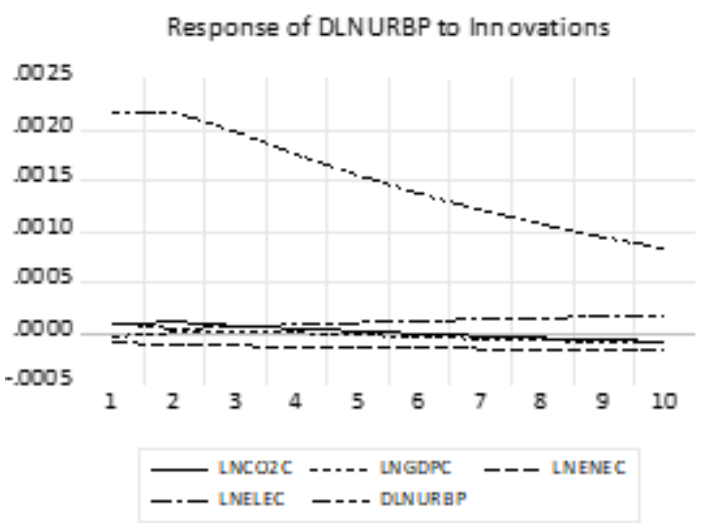

Figure 3. Impulse-Response functions in the VEC model with one-lag dependence (Model A) Source: Own elaboration, with data from the WBDB.

lnCO2C strongly responds to previous $\operatorname{lnCO} 2 \mathrm{C}$ innovations, although its response to other variables is weak. The most vigorous response is to the previous two-year dlnURBP. Similarly, the response of $\operatorname{lnGDPC}$ is strong to former lnGDPC impulses. However, it also shows a positive response to $\operatorname{lnCO} 2 \mathrm{C}$ impulses, and a negative response to changes of lnURBP impulses, with an increasingly noticeable response the longer the period of observation is. $\operatorname{lnENEC}$ responds to previous $\operatorname{lnENEC}, \operatorname{lnCO} 2 \mathrm{C}$, and $\operatorname{lnGDPC}$ impulses, in that order of magnitude. InELEC responds to previous periods impulses from lnELEC, InENEC $\operatorname{lnCO} 2 \mathrm{C}$, and $\operatorname{lnGDPC}$, in that order of magnitude; it also exhibits a negative response to the impulse from dlnURBP, which increases with the number of periods. Finally, dlnURBP mainly responds to its impulse with diminishing strength, the longer the period after the impulse takes place.

The estimation of Model B allows for changes in the number of lags to optimize its adjustment. The version that attains a better overall AIC contains thirteen lags. The JCT shows that no cointegration vectors exist for the variables under analysis. The probability of no cointegration equations is 88.2 percent and 61.9 percent, according to the trace and the ME statistics, respectively (see Table 6), below.

Tabla 6. Johansen cointegration test, Model B

Unrestricted Cointegration Rank Test (Trace)

\begin{tabular}{|c|c|c|c|}
\hline $\begin{array}{c}\text { Hypotesized } \\
\text { number of } \\
\text { cointegration } \\
\text { equations(s) }\end{array}$ & Trace Statistic & $\begin{array}{c}\mathbf{0 . 0 5} \\
\text { Critical } \\
\text { Value }\end{array}$ & Probability*** \\
\hline None & 43.242 & 69.819 & 0.882 \\
\hline At most 1 & 21.396 & 47.856 & 0.981 \\
\hline At most 2 & 6.472 & 29.797 & 0.999 \\
\hline
\end{tabular}

Unrestricted Cointegration Rank Test (Maximum Eigenvalue) 


\begin{tabular}{|c|c|c|c|}
\hline $\begin{array}{c}\text { Hypothesized } \\
\text { number of } \\
\text { cointegration } \\
\text { equations(s) }\end{array}$ & $\begin{array}{c}\text { Maximum } \\
\text { Eigenvalue } \\
\text { Statistic }\end{array}$ & $\begin{array}{c}\mathbf{0 . 0 5} \\
\text { Critical } \\
\text { Value }\end{array}$ & Probability** \\
\hline None & 21.846 & 33.877 & 0.619 \\
\hline At most 1 & 14.924 & 27.584 & 0.754 \\
\hline At most 2 & 4.476 & 21.131 & 0.998 \\
\hline
\end{tabular}

Note: **MacKinnon-Haug-Michelis (1999) p-values

Source: Own elaboration, with data from the WBDB.

Therefore, Model B is estimated with a VAR specification (with no cointegration equations) and is reported in Table 7. The estimation results indicate that dlnCO2C statistically depends on its sixth lag, on dlnENEC's sixth lag, and on d2InURBP's tenth lag. All other variables, including dlnGDPC, are not statistically significant at a 95 percent confidence level. Other interesting relations are that dlnGDPC has a significant statistical relation with the lags of all variables in the model. The coefficients for dinENEC show that the only statistically significant relationship of this variable is to its fifth-period lag and with the fist lag of d2lnURBP. dlnELEC has a statistically significant relationship with the second and fourth through sixth lags of dlnCO2C, as well as dlnENEC (fifth lag) and dELEC (first, third and seventh lags), and to d2URBP (fifth through seventh and ninth lags). Finally, d2lnURBP has a statistically significant relation with the first lags of dlnGDPC and dlnELEC, and with the fifth, eight, eleventh and twelfth lags of d2lnURBP.

Table 7. Model B, VAR model with 13 lags

\begin{tabular}{|c|c|c|c|c|c|}
\hline & dlnCO2C & dlnGDPC & dlnENEC & dlnELEC & d2InURBP \\
\hline $\mathrm{d} \operatorname{lnCO} 2 \mathrm{C}(-1)$ & -0.222 & 0.0364 & -0.0084 & 0.0672 & 0.0004 \\
\hline $\mathrm{d} \operatorname{lnCO} 2 \mathrm{C}(-2)$ & -0.1654 & -0.0333 & -0.0916 & $0.1632^{*}$ & 0.0006 \\
\hline $\mathrm{d} \operatorname{lnCO} 2 \mathrm{C}(-3)$ & 0.1324 & 0.0492 & 0.103 & 0.1292 & 0 \\
\hline $\mathrm{d} \ln \mathrm{CO} 2 \mathrm{C}(-\mathrm{x})^{* *}$ & $6-$ & $6-$ & & $4+, 5+, 6-$ & \\
\hline $\mathrm{d} \ln \mathrm{GDPC}(-1)$ & 0.1669 & $0.3148^{*}$ & 0.0894 & 0.2904 & $-0.0041^{*}$ \\
\hline $\mathrm{d} \ln \mathrm{GDPC}(-2)$ & -0.0761 & 0.1212 & -0.0356 & 0.0388 & -0.0008 \\
\hline $\mathrm{d} \ln \mathrm{GDPC}(-3)$ & 0.0607 & -0.047 & 0.0961 & -0.1057 & -0.0008 \\
\hline $\mathrm{d} \operatorname{lnGDPC}(-\mathrm{x})^{* *}$ & & $7+, 9-$ & & & \\
\hline $\mathrm{d} \operatorname{lnENEC}(-1)$ & 0.184 & 0.0767 & -0.0987 & 0.1259 & -0.0011 \\
\hline $\mathrm{d} \operatorname{lnENEC}(-2)$ & 0.0055 & 0.0716 & 0.0583 & -0.1291 & 0.0003 \\
\hline $\mathrm{d} \operatorname{lnENEC}(-3)$ & -0.0884 & 0.002 & -0.0086 & -0.0628 & 0.0011 \\
\hline $\mathrm{d} \operatorname{lnENEC}(-\mathrm{x})^{* *}$ & $6+$ & $6+$ & $5-$ & $5-$ & \\
\hline $\mathrm{d} \operatorname{lnELEC}(-1)$ & 0.1591 & -0.0578 & 0.0944 & $-0.2482^{*}$ & $0.0022^{*}$ \\
\hline $\mathrm{d} \operatorname{lnELEC}(-2)$ & 0.1483 & -0.0173 & -0.043 & -0.1281 & -0.001 \\
\hline $\mathrm{d} \operatorname{lnELEC}(-3)$ & -0.0685 & 0.0222 & -0.027 & $0.2441^{*}$ & -0.001 \\
\hline
\end{tabular}




\begin{tabular}{|c|c|c|c|c|c|}
\hline $\mathrm{d} \ln \operatorname{ELEC}(-\mathrm{x}) * *$ & & $6-, 7+, 8+$ & & $7+$ & \\
\hline $\mathrm{d} 2 \ln U R B P(-1)$ & -20.0218 & -3.7755 & $-26.2277 *$ & -10.4579 & $0.1676^{*}$ \\
\hline $\mathrm{d} 2 \mathrm{nURBP}(-2)$ & 2.4904 & 1.0058 & 5.6022 & -8.64 & 0.0077 \\
\hline $\mathrm{d} 2 \ln U R B P(-3)$ & 1.4293 & $-5.2053 *$ & -6.3724 & 0.989 & -0.0225 \\
\hline $\mathrm{d} \ln \operatorname{URBP}(-\mathrm{x})^{* *}$ & $10-$ & $4-, 7-, 12-$ & & 5-,6-,7-,9- & 5-,8-,11-,12- \\
\hline $\begin{array}{l}\text { Adjusted } R \\
\text { squared }\end{array}$ & 0.086 & 0.217 & 0.255 & 0.594 & 0.289 \\
\hline $\begin{array}{c}\text { Akaike } \\
\text { information } \\
\text { criterion } \\
\end{array}$ & -2.111 & -4.127 & -2.825 & -2.997 & -12.349 \\
\hline $\begin{array}{c}\text { Overall Akaike } \\
\text { information } \\
\text { criterion }\end{array}$ & -25.229 & & & & \\
\hline
\end{tabular}

Figure 4 illustrates the impulse-response functions for the VAR model with independent variables up to thirteen lags. The accumulated response of $\mathrm{d} \operatorname{lnCO} 2 \mathrm{C}$ is strong to its impulse, while its positive accumulated response to innovations in dlnGDPC, dlnENEC, and dlnELEC is mild but marginally increasing through time. By contrast, dlnCO2C's response to the impulse of d2lnURBP is negative. Here, the dlnGDC most substantial accumulated response is to its innovations, and it also responds to dlnENEC, dlnELEC, and d2lnURBP increases with time, with a negative accumulated response to the latter.

The dlnENEC shows a persistent accumulated response from its lag and lagged dlnCO2C. The variable dlnENEC also responds positively but in a weaker fashion to impulses from dlnGDPC and dlnENEC. its response to dlnURBP impulses is negative. dlnELEC has an accumulated persistent positive response to its innovations, to dlnGDPC, and $\operatorname{lnCO} 2 \mathrm{C}$ impulses, in that order of importance; its accumulated response to d2lnURBP impulses is negative and increases with the number of periods. d2lnURBP accumulated response to its impulses is comparatively strong but marginally diminishes with the length of time after the third period. This variable also responds to dlnGDPC, but with a negative tendency. Its response to other variables is weak.

The response to dlnGDPC to dlnENEC reinforce the observed relation of energy use and economic growth observed for Latin-American countries in Al-Mulali et al. (2015), similar results were also found elsewhere (Wolde-Rufael, 2005; Halicioglu, 2009, Pablo-Romero and De Jesus, 2016). 
Response to Cholesky One S.D. (d.f. adjusted) Innovations
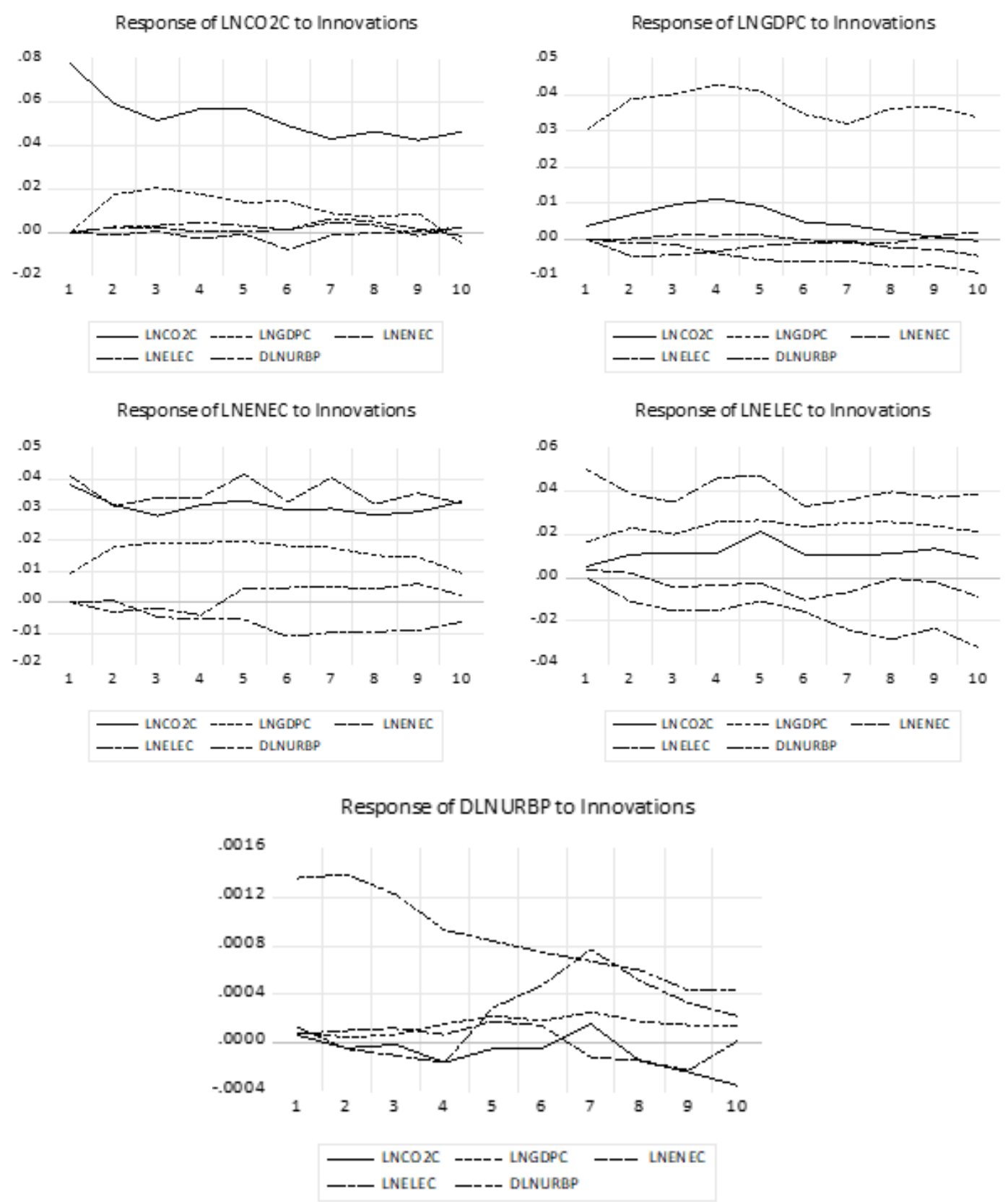

Figure 4. Impulse Response in the VAR Model with thirteen lags dependence (Model B) Source: Own elaboration, with data from the WBDB.

As described earlier in this paper, the EKC is an inverted U-shaped relationship between $\mathrm{CO} 2$ emissions and GDP. The relation implies that the slope of the graphical representation of CO2 emissions (vertical axis) to GDPC (horizontal axis) should change from positive, to flat (zero slope), and then to negative, as GDPC increases from low to medium levels, and then to a high level. Another way to visualize the relationship between $\mathrm{CO} 2$ emissions and GDPC is by estimating a dynamic Kuznets type relation, in which the marginal change of $\mathrm{CO} 2$ emissions per capita to the lagged marginal change of GDPC 
$\left(\mathrm{dCO}_{2} \mathrm{C}_{t} / \mathrm{dGDPC}_{t-1}\right)$. According to the conceptualization of the EKC relation in terms of $\mathrm{dCO} 2 \mathrm{C}_{t} / \mathrm{dGDPC}_{t}$ ${ }_{1}$, when moving from a low level of GDPC to a medium level (second derivative of the relationship), the difference should be negative. However, the results of this analysis were inconclusive (see Table 8) because that relationship is not satisfied from low to medium GDPC $\left(\mathrm{dCO} 2 \mathrm{C}_{t} / \mathrm{dGDPC}_{t-1}\right.$ increases with GDPCAPt1 from 0.0000043 to 0.0000148 ). The relationship is, however, satisfied from medium to high GDPC; i.e., the $\mathrm{dCO}_{2} \mathrm{C}_{t} / \mathrm{dGDPC}_{t-1}$ decreases with $\mathrm{GDPC}_{t-1}$ (from 0.0000148 to -0.0000051 ). The result contrasts with Al-Mulali's (2015), which finds that there is EKC for its Latin-American countries sample.

Table 8. Relations between emission per capita and previous year growth per capita

\begin{tabular}{|c|c|c|c|c|}
\hline GDPC & Mean CO2C & Mean GDPC & Elasticity & $\begin{array}{c}\text { dCO2C }_{\boldsymbol{t}} \text { ( } \\
\text { dGDPC }_{\boldsymbol{t} \mathbf{- 1}}\end{array}$ \\
\hline High & 0.868 & 4,698 & -0.0277 & -0.0000051 \\
\hline Medium & 1.652 & 9,701 & 0.0871 & 0.0000148 \\
\hline Low & 3.627 & 14,760 & 0.0175 & 0.0000043 \\
\hline
\end{tabular}

Notes: Low, medium, and high refer to the respective tercile division of the countries with respect to GDPC in 1990. Elasticity is that of $\mathrm{CO}_{2} \mathrm{C}_{t}$ to $\mathrm{GDPC}_{t-1}$. All elasticities are not statistically different from zero with a $95 \%$ confidence level.

\section{Conclusions}

The VEC (VAR) models estimated to gain an insight on the relations between $\mathrm{CO} 2$ emissions per capita (CO2C), GDP per capita (GDPC), energy consumption (ENEC), electricity consumption (ELEC) provide interesting evidence for a sample of nineteen LA countries (Argentina, Bolivia, Brazil, Chile, Colombia, Costa Rica, Dominican Republic, Ecuador, El Salvador, Guatemala, Haiti, Honduras, Mexico, Nicaragua, Panama, Paraguay, Peru, Uruguay, and Venezuela.) in the sample of observations retrieved from the World Bank Data Base for a period that runs from 1990 to 2014. The results obtained indicate that changes in CO2 emissions per capita depend on previous GDP growth is ambiguous. From model A, the changes in the logarithm of $\mathrm{CO} 2$ emissions per capita statistically depends on the previous changes in the logarithm of GDP per capita, but the cointegration relation does not have the GDP related variable as a statistically explanatory variable, by contrast with studies from other latitudes. In Model B, the changes in $\mathrm{CO} 2$ emissions per capita only statistically depend on previous own changes, previous changes in energy use per capita, and second changes in the proportion of the urban population to the total population. The statistical dependency on the changes in the logarithm of GDP per capita only is relevant because this variable affects the second changes in the proportion of the urban population to the total population. The accumulated response of $\mathrm{CO} 2$ emissions mainly depends on previous $\mathrm{CO} 2$ impulses. The response to changes of other variables, including GDP per capita, only becomes noticeable after many periods.

The dynamic Kuznets relation, in which the first derivative of $\mathrm{CO} 2$ emissions per capita to the first lag of GDP per capita must be decreasing with GDP per capita, is only partially satisfied (in the case of the change from countries with a medium to a high level of GDP per capita). However, it is not satisfied with the change from countries with a low to medium per capita GDP.

Interestingly, the changes in the logarithm of the proportion of the urban population to the total population are relevant to explain changes in the logarithm of $\mathrm{CO} 2$ emissions per capita, GDP per capita, 
energy and electricity use per capita, and the proportion of the urban population itself. In model A, the changes in the logarithm of the proportion of the urban population to the total population are statistically significant in the cointegration equation to explain $\mathrm{CO} 2$ emissions per capita. This equation is statistically significant to explain changes in the logarithms of $\mathrm{CO} 2$ emissions per capita, GDP per capita, and electricity use per capita, and the second changes in the logarithm of the proportion of the urban population to the total population. The second differences in the logarithm of the urban population are statistically significant to explain the changes in the logarithms of $\mathrm{CO} 2$ emissions, GDP per capita, and second differences themselves. In Model B, lags of the second difference of the logarithm of the proportion of the urban population to the total population statistically explain each of the model variables. The main driver in LA for changes in CO2 emissions per capita, GDP per capita, energy, and electricity use per capita, and the urbanization process appears to be the urbanization process itself.

Regarding the energy and electricity use, in Model A, the changes in the logarithm of energy use are statistically dependent on previous changes of the logarithms of GDP per capita and energy use per capita. In Model B, the changes in energy use statistically depend on previous second changes of the urban population to the total population and previous changes in energy use. Electricity use in Latin America responds to previous $\mathrm{CO} 2$ emissions, energy and electricity use, and urbanization. In Model A, the changes in the electricity use per capita, in the long run, are represented by the cointegration equation, which statistically relates $\mathrm{CO} 2$ emission per capita and changes in the proportion of the urban population to the total population. Besides, they are related to previous changes in the logarithm of electricity use per capita. In Model B, they are also related to the previous changes in the logarithms of CO2 emissions, energy, and electricity use per capita, and the second changes of the logarithm of the proportion of the urban population to the total population.

The increased interest on the interaction among economic growth, energy consumption, $\mathrm{CO} 2$ emissions, and urbanization, as a consequence of the significant structural transformations that are taking place on the energy markets, frequently associated to geopolitical forces, and a rapidly developing global conscience of the significant negative consequences of global warming and its association with $\mathrm{CO} 2$ emissions to the atmosphere, requires a better understanding of the economic and social impacts of modifying the current energy generation and consumption patterns. The empirical results may be useful for the designers and supervisors of public policies on urbanization, energy, and the environment. However, the results, particularly those related to the Kuznets relation, are limited given the study timespan and the homogeneity of the Latin American countries. Nevertheless, we recommend further analysis in the interaction of economic growth, energy consumption, $\mathrm{CO} 2$ emissions, and urbanization and the inclusion of a more diverse sample of countries.

\section{References}

[1] Aali-Bujari, A., Venegas-Martínez, F., and Palafox-Roca, A.O. (2017), Impact of energy consumption on economic growth in major OECD economies (1977-2014): A panel data approach. International Journal of Energy Economics and Policy, 7(2), 1-8. https://doi.org/10.32479/ijeep.7120

[2] Acaravci, A., and Ozturk, I. (2010). On the relationship between energy consumption, $\mathrm{CO} 2$ emissions and economic growth in Europe. Energy, 35(12), 5412-5420. https://doi.org/10.1016/j.energy.2010.07.009 
[3] Ahmad, A., Zhao, Y., Shahbaz, M., Bano, S., Zhang, Z., Wang, S., and Liu, Y. (2016). Carbon emissions, energy consumption and economic growth: An aggregate and disaggregate analysis of the Indian economy. Energy Policy, 96, 131-143. https://doi.org/10.1016/j.enpol.2016.05.032

[4] Ajmi, A. N., Hammoudeh, S., Nguyen, D. K., and Sato, J. R. (2015). On the relationships between CO2 emissions, energy consumption and income: The importance of time variation. Energy Economics, 49, 629638. https://doi.org/10.1016/j.eneco.2015.02.007

[5] Akinlo, A.E. (2008). Energy consumption and economic growth: Evidence from 11 Sub-Sahara African countries. Energy Economics, 30(5), 2391-2400. https://doi.org/10.1016/j.eneco.2008.01.008

[6] Al-Mulali, U., Lee, J. Y., Hakim Mohammed, A., and Sheau-Ting, L. (2013). Examining the link between energy consumption, carbon dioxide emission, and economic growth in Latin America and the Caribbean. Renewable and Sustainable Energy Reviews, 26, 42-48. https://doi.org/10.1016/j.rser.2013.05.041

[7] Al-Mulali, U., Tang, C. F., and Ozturk, I. (2015). Estimating the Environment Kuznets Curve hypothesis: Evidence from Latin America and the Caribbean countries. Renewable and Sustainable Energy Reviews, 50, 918-924. https://doi.org/10.1016/j.rser.2015.05.017

[8] Alam, M. J., Begum, I. A., Buysse, J., Rahman, S., and Van Huylenbroeck, G. (2011). Dynamic modeling of causal relationship between energy consumption, CO 2 emissions and economic growth in India. Renewable and Sustainable Energy Reviews, 15(6), 3243-3251. https://doi.org/10.1016/j.rser.2011.04.029

[9] Aldy, J. E. (2005). An Environmental Kuznets Curve analysis of U.S. state-level carbon dioxide emissions. Journal of Environment and Development, 14(1), 48-72. https://doi.org/10.1177/1070496504273514

[10] Ang, J. B. (2007). CO2 emissions, energy consumption, and output in France. Energy Policy, 35(10), 47724778. https://doi.org/10.1016/j.enpol.2007.03.032

[11] Antonakakis, N., Chatziantoniou, I., and Filis, G. (2017). Energy consumption, CO2 emissions, and economic growth: An ethical dilemma. Renewable and Sustainable Energy Reviews, 68, 808-824. https://doi.org/10.1016/j.rser.2016.09.105

[12] Apergis, N., and Payne, J. E. (2009). Energy consumption and economic growth: Evidence from the Commonwealth of Independent States. Energy Economics, 31(5), 641-647. https://doi.org/10.1016/j.eneco.2009.01.011

[13] Bartleet, M., and Gounder, R. (2010). Energy consumption and economic growth in New Zealand: Results of trivariate and multivariate models. Energy Policy, 38(7), 3508-3517. https://doi.org/10.1016/j.enpol.2010.02.025

[14] Beckerman, W., 1992. Economic growth and the environment: Whose growth? Whose environment? World Development, 20(4), 481-496. https://doi.org/10.1016/0305-750X(92)90038-W

[15] Bella, G., Massidda, C., and Mattana, P. (2014). The relationship among CO2 emissions, electricity power consumption and GDP in OECD countries. Journal of Policy Modeling, 36(6), 970-985. https://doi.org/10.1016/j.jpolmod.2014.08.006

[16] Cai, Y., Sam, C. Y., and Chang, T. (2018). Nexus between clean energy consumption, economic growth and CO2 emissions. Journal of Cleaner Production, 182, 1001-1011. https://doi.org/10.1016/j.jclepro.2018.02.035

[17] Cerdeira Bento, J. P., and Moutinho, V. (2016). CO2 emissions, non-renewable and renewable electricity production, economic growth, and international trade in Italy. Renewable and Sustainable Energy Reviews, 55, 142-155. https://doi.org/10.1016/j.rser.2015.10.151

[18] Chang, C. C. (2010). A multivariate causality test of carbon dioxide emissions, energy consumption and economic growth in China. Applied Energy, 87(11), 3533-3537. https://doi.org/10.1016/j.apenergy.2010.05.004 
[19] Chang, C. C., and Soruco Carballo, C. F. (2011). Energy conservation and sustainable economic growth: The case of Latin America and the Caribbean. Energy Policy, 39(7), 4215-4221. https://doi.org/10.1016/j.enpol.2011.04.035

[20] Cheng, B.S., 1997. Energy consumption and economic growth in Brazil, Mexico and Venezuela: a time series analysis. Applied Economics Letters, 4(11), 671-674.

[21] Choi, I. 2001. Unit root tests for panel data. Journal of International Money and Finance 20(2): 249-272. https://doi.org/10.1016/S0261-5606(00)00048-6

[22] De Barbosa, L. S. N. S., Bogdanov, D., Vainikka, P., and Breyer, C. (2017). Hydro, wind and solar power as a base for a 100\% renewable energy supply for South and Central America. PLOS ONE, 12(3), 1-28. https://doi.org/10.1371/journal.pone.0173820

[23] Demir, C., Cergibozan, R., and Gök, A. (2019). Income inequality and CO 2 emissions: Empirical evidence from Turkey. Energy and Environment, 30(3), 444-461. https://doi.org/10.1177/0958305X18793109

[24] Dinda, S. (2004). Environmental Kuznets Curve hypothesis: A survey. Ecological Economics, 49(4), 431455. https://doi.org/10.1016/j.ecolecon.2004.02.011

[25] Gao, J., and Zhang, L. (2014). Electricity Consumption-economic growth-CO2 Emissions nexus in subsaharan Africa: Evidence from panel cointegration. African Development Review, 26(2), 359-371. https://doi.org/10.1111/1467-8268.12087

[26] Ghali, K.H., El-Sakka, M.I.T., 2004. Energy use and output growth in Canada: a multivariate cointegration analysis. Energy Economics, 26, 225-238. https://doi.org/10.1016/S0140-9883(03)00056-2

[27] Ghosh, S. (2010). Examining carbon emissions economic growth nexus for India: A multivariate cointegration approach. Energy Policy, 38(6), 3008-3014. https://doi.org/10.1016/j.enpol.2010.01.040

[28] Gorus, M. S., and Aydin, M. (2019). The relationship between energy consumption, economic growth, and CO 2 emission in MENA countries: Causality analysis in the frequency domain. Energy, 168, 815-822. https://doi.org/10.1016/j.energy.2018.11.139

[29] Halicioglu, F., 2009. An econometric study of CO2 emissions, energy consumption, income and foreign trade in Turkey. Energy Policy, 37(3), 1156-1164. https://doi.org/10.1016/j.enpol.2008.11.012

[30] Heidari, H., Turan Katircioğlu, S., and Saeidpour, L. (2015). Economic growth, CO2 emissions, and energy consumption in the five ASEAN countries. International Journal of Electrical Power and Energy Systems, 64, 785-791. https://doi.org/10.1016/j.ijepes.2014.07.081

[31] Huang, B. N., Hwang, M. J., and Yang, C. W. (2008). Causal relationship between energy consumption and GDP growth revisited: A dynamic panel data approach. Ecological Economics, 67(1), 41-54. https://doi.org/10.1016/j.ecolecon.2007.11.006

[32] Kaika, D., and Zervas, E. (2013). The Environmental Kuznets Curve (EKC) theory-Part A: Concept, causes and the CO2 emissions case. Energy Policy, 62, 1392-1402. https://doi.org/10.1016/j.enpol.2013.07.131

[33] Kuznets, S. (1955) Economic growth and income inequality, American Economic Review, 45(1), 1-28. Retrieved from https://www.jstor.org/stable/1811581

[34] Kasman, A., and Duman, Y. S. (2015). CO2 emissions, economic growth, energy consumption, trade and urbanization in new EU member and candidate countries: A panel data analysis. Economic Modelling, 44, 97-103. https://doi.org/10.1016/j.econmod.2014.10.022

[35] Mikayilov, J. I., Hasanov, F. J., and Galeotti, M. (2018). Decoupling of CO 2 emissions and GDP: A timevarying cointegration approach. Ecological Indicators, 95, 615-628. https://doi.org/10.1016/j.ecolind.2018.07.051

[36] Narayan, P. K., and Popp, S. (2012). The energy consumption-real GDP nexus revisited: Empirical evidence from 93 countries. Economic Modelling, 29(2), 303-308. https://doi.org/10.1016/j.econmod.2011.10.016

[37] Narayan P. K, and Smyth R. (2009). Multivariate granger causality between electricity consumption, exports and GDP: evidence from a panel of Middle Eastern countries. Energy Policy, 37, 229-36. https://doi.org/10.1016/j.enpol.2008.08.020 
[38] Niu, S., Ding, Y., Niu, Y., Li, Y., Luo, G., (2011). Economic growth, energy conservation and emissions reduction: a comparative analysis based on panel data for 8 Asian-Pacific countries. Energy Policy, 39, 21212131. https://doi.org/10.1016/j.enpol.2011.02.003

[39] Omri, A. (2014). An international literature survey on energy-economic growth nexus: Evidence from country-specific studies. Renewable and Sustainable Energy Reviews, 38, 951-959. https://doi.org/10.1016/j.rser.2014.07.084

[40] Ozturk, I. (2010). A literature survey on energy-growth nexus. Energy Policy, 38(1), 340-349. https://doi.org/10.1016/j.enpol.2009.09.024

[41] Ozturk, I., and Acaravci, A. (2010). CO2 emissions, energy consumption and economic growth in Turkey. Renewable and Sustainable Energy Reviews, 14(9), 3220-3225. https://doi.org/10.1016/j.rser.2010.07.005

[42] Pablo-Romero, M. D. P., and De Jesús, J. (2016). Economic growth and energy consumption: The EnergyEnvironmental Kuznets Curve for Latin America and the Caribbean. Renewable and Sustainable Energy Reviews, 60, 1343-1350. https://doi.org/10.1016/j.rser.2016.03.029

[43] Pao, H. T., and Tsai, C. M. (2010). CO 2 emissions, energy consumption and economic growth in BRIC countries. Energy Policy, 38(12), 7850-7860. https://doi.org/10.1016/j.enpol.2010.08.045

[44] Payne, J. E. (2010). A survey of the electricity consumption-growth literature. Applied Energy, 87(3), 723731. https://doi.org/10.1016/j.apenergy.2009.06.034

[45] Richard, O. O. (2012). Energy consumption and economic growth in sub-Saharan Africa: An asymmetric cointegration analysis. Economie Internationale, 129(1), 99-118. https://doi.org/10.1016/s21107017(13)60050-5

[46] Saboori, B., Sulaiman, J., and Mohd, S. (2012). Economic growth and CO 2 emissions in Malaysia: A cointegration analysis of the Environmental Kuznets Curve. Energy Policy, 51, 184-191. https://doi.org/10.1016/j.enpol.2012.08.065

[47] Saidi, K., and Hammami, S. (2015). The impact of CO2 emissions and economic growth on energy consumption in 58 countries. Energy Reports, 1, 62-70. https://doi.org/10.1016/j.egyr.2015.01.003

[48] Squalli J.2007. Electricity consumption and economic growth: bounds and causality analyses of OPEC countries. Energy Economics, 29, 1192-1205. https://doi.org/10.1016/j.eneco.2006.10.001

[49] Salazar-Núñez, H. F., Venegas-Martínez, F., and Tinoco-Zermeño, M. A. (2020) Impact of Energy Consumption and Carbon Dioxide Emissions on Economic Growth: Cointegrated Panel Data in 79 Countries Grouped by Income Level, International Journal of Energy Economics and Policy, 10(2), 218-226. https://doi.org/10.32479/ijeep.8783

[50] Solarin, S. A., and Ozturk, I. (2015). On the causal dynamics between hydroelectricity consumption and economic growth in Latin America countries. Renewable and Sustainable Energy Reviews, 52, 1857-1868. https://doi.org/10.1016/j.rser.2015.08.003

[51] Soytas, U., Sari, R., 2009. Energy consumption, economic growth, and carbon emissions: challenges faced by an EU candidate member. Ecological Economics, 68 (6), 1667-1675. https://doi.org/10.1016/j.ecolecon.2007.06.014

[52] Tateishi, R.H.; Bittencourt da Silva, P.F.; Dias Aguiar, D.R.; Bragagnolo C. (2017) The Relationship Between Economic Growth, Energy Consumption, and Pollution: Evidences from Brazil. International Journal of Energy, Environment and Economics, 25(2), 579-612.

[53] Tiba, S., and Omri, A. (2017). Literature survey on the relationships between energy, environment and economic growth. Renewable and Sustainable Energy Reviews, 69(82555), 1129-1146. https://doi.org/10.1016/j.rser.2016.09.113

[54] Tiwari, A. K., Shahbaz, M., and Adnan Hye, Q. M. (2013). The environmental Kuznets curve and the role of coal consumption in India: Cointegration and causality analysis in an open economy. Renewable and Sustainable Energy Reviews, 18, 519-527. https://doi.org/10.1016/j.rser.2012.10.031 
[55] Wolde-Rufael, Y., 2005. Energy demand and economic growth: the African experience. Journal of Policy Modeling. 27(8), 891-903. https://doi.org/10.1016/j.jpolmod.2005.06.003

[56] Zambrano-Monserrate, M. A., Silva-Zambrano, C. A., Davalos-Penafiel, J. L., Zambrano-Monserrate, A., and Ruano, M. A. (2018). Testing environmental Kuznets curve hypothesis in Peru: The role of renewable electricity, petroleum and dry natural gas. Renewable and Sustainable Energy Reviews, 82, 4170-4178. https://doi.org/10.1016/j.rser.2017.11.005

[57] Zhang, X. P., and Cheng, X. M. (2009). Energy consumption, carbon emissions, and economic growth in China. Ecological Economics, 68(10), 2706-2712. https://doi.org/10.1016/j.ecolecon.2009.05.011

[58] Zhang, Y. J. (2011). Interpreting the dynamic nexus between energy consumption and economic growth: Empirical evidence from Russia. Energy Policy, 39(5), 2265-2272. https://doi.org/10.1016/j.enpol.2011.01.024 